\title{
ANÁLISE DE CONTEÚDO E PESQUISA NA ÁREA DA EDUCAÇÃ̃O ${ }^{1}$
}

\author{
The content analysis and research in the \\ educational field
}

\author{
Eliana de Oliveira* \\ Romilda Teodora Ens \\ Daniela B. S. Freire Andrade \\ Carlo Ralph de Mussis
}

\section{Resumo}

O presente texto, sobre o uso da análise de conteúdo na área da educação, procura ser uma contribuição à pesquisa em educação no sentido de colocar à disposição do pesquisador este importante procedimento de interpretação de dados coletados. A partir deste propósito, o texto responde as seguintes questões: o que é análise de conteúdo, o que faz dela um método durável, confiável, sendo plenamente aceito até mesmo por revistas internacionais de grande rigor científico e metodológico? Quais são as etapas de sua execução? Como estas etapas se estruturam? E finalmente, quais são os limites da análise de conteúdo? Para respondê-las, este texto usa exemplos que clareiam o processo de análise de conteúdo.

Palavras-chave: Pesquisa, Análise de conteúdo, Metodologia de pesquisa.

* Doutoranda em Psicologia Social da Ecole des Hautes Etudes em Sciences Sociales - Paris/França. E-mail: elianadolive@hotmail.com

* Professora e pesquisadora da Pontíficia Universidade Católica do Paraná. Doutoranda do Programa de Estudos Pós-Graduados em Educação: Psicologia da Educação - Pontífice Universidade Católica de São Paulo. E-mail: romilda@bruc.com.br

* Professora e pesquisadora da Universidade Federal de Mato Grosso. Doutoranda do Programa de Estudos Pós-Graduados em Educação: Psicologia da Educação - Pontífice Universidade Católica de São Paulo. E-mail: freire.d@terra.com.br

*** Doutorando do Programa de Estudos Pós-Graduados em Educação: Psicologia da Educação - Pontífice Universidade Católica de São Paulo. E-mail: crdemusis@terra.com.br 


\section{Résumé}

Ce texte sur l'utilisation de l'analyse de contenu dans le domaine de l'éducation veut être une contribution à la recherche en Education, dans le sens de mettre à disposition du chercheur cette importante procédure d'interprétation des données collectées. Dans ce but, le texte répond aux questions suivantes: qu'estce l'analyse de contenu? Qu'est ce que la fait devenir une méthode durable, crédible, pleinement acceptée dans des revues internationales de grande rigueur scientifique et méthodologique? Quelles sont les étapes de son exécution? Comment ces étapes sont-elles structurées? Et finalement, quelles sont les limites de l'analyse de contenu? Pour y apporter des réponses ce texte s'en sert des exemples qui éclaircissent le processus de l'analyse de contenu.

Mots-cléfs: Recherche, Analyse decontenu, Methodologie de la recherche.

\section{A análise de conteúdo no contex to da produção do conhecimento}

A análise de conteúdo, instrumento de análise interpretativa, é uma das técnicas de pesquisa mais antigas - os primórdios de sua utilização remontam a 1787 nos Estados Unidos, e sua emergência como método de estudo aconteceu nas décadas de 20 e 30 do século passado com o desenvolvimento das Ciências Sociais, quando a ciência clássica entrava em crise. Como se sabe, a atitude interpretativa faz parte do ser humano que deseja atingir o conhecimento. Desde a hermenêutica, arte de interpretar os textos sagrados ou misteriosos, o homem praticava a interpretação como forma de colocar a sua observação sobre um dado fenômeno.

No século passado, esta atitude interpretativa subjacente ao homem buscara se adaptar às normas científicas. Lasswell (1915) usou a análise de conteúdo para realizar análise da imprensa e de propaganda nos Estados Unidos. A atitude interpretativa, que emerge dessa técnica de análise, diferenciase da hermenêutica. Os problemas suscitados pela Segunda Guerra Mundial favoreceram os estudos empíricos que utilizaram a técnica de análise de conteúdo no campo da política, sob a forma de pesquisas pragmáticas.

Como explicar esta nova atitude empirica que se distancia da hermenêutica? Ao analisar a história do desenvolvimento da ciência, observase que esta se constitui como conhecimento sistematizado, construído historicamente pelo homem para conhecer a realidade, e verifica-se que as demandas que incentivam a produção científica correspondem às necessidades de quem a produz ou de quem está interessado nessa produção. O conhecimento e a análise interpretativa do próprio conhecimento é, assim, uma construção que parte da realidade concreta, histórica e social dos homens. 
Mais tarde, ao final dos anos 40-50 do século passado, impregnado pelo conhecimento simplificador, Berelson (1954) apud Bardin (1979, p. 18) definiu a análise de conteúdo ao dizer: "é uma técnica de investigação que tem por finalidade a descrição objetiva, sistemática e quantitativa do conteúdo manifesto da comunicação".

Neste peníodo, os critérios estabelecidos por Lasswell e Berelson (1954) apud Bardin (1979, p. 19) corresponderam a preocupação em trabalhar com amostras reunidas de maneira sistemática, em interrogar-se sobre a validade dos procedimentos e dos resultados, em verificar a fidelidade dos codificadores e até a medir a produtividade da análise.

A crise da certeza, frente à complexidade inerente aos dados, contribuiu para emergir uma proposta para o enfrentamento das incertezas. Esta crise das ciências exigiu uma nova maneira de interpretar os objetos investigados, e no plano metodológico-epistemológico se exigiu deixar de lado a dicotomia quantidade/qualidade. É o próprio Berelson (1959) apud Bardin (1979, p. 20) que desencantado com o rumo do processo de análise de conteúdo afirmou: "A análise de conteúdo como método, não possui qualidades mágicas e raramente se retira mais do que nela se investe e algumas vezes até menos; - no fim de contas, nada há que substitua as idéias brilhantes".

Idéias brilhantes se fazem necessárias, pois o pesquisador busca pelo método de análise de conteúdo, segundo Bardin (1979, p.29), ultrapassar as incertezas e o enriquecimento da leitura, tendo por base um modelo formal calcado na necessidade de descobrir, pelo questionamento: $\mathrm{O}$ que vejo, por exemplo, na mensagem, está realmente contido nela? Outros podem compartilhar a minha visão ou ela é muito pessoal? Ela vai além das aparências?

O campo de aplicação da análise de conteúdo se torna cada vez mais vasto. Isto fez Henry e Moscovici (1968) apud Bardin (1979, p. 33) dizerem: "tudo o que é dito ou escrito é suscetível de ser submetido a uma análise de conteúdo". Ou, ainda, lembra a expressão de Lasswell, Lener e Pool apud Bardin (1979, p. 13) "a análise de conteúdo deve começar onde os modos tradicionais de investigação acabam".

Bardin (1979, p.42) resume o terreno, o funcionamento e o objetivo da análise de conteúdo ao explicitar que o termo análise de conteúdo é:

Um conjunto de técnicas de análise das comunicações visando obter, por procedimentos, sistemáticos e objetivos de descrição do conteúdo das mensagens, indicadores (quantitativos ou não) que permitam a inferência de conhecimentos relativos às condições de produção/recepção (variáveis inferidas) destas mensagens.

A abordagem de análise de conteúdo tem por finalidade, a partir de um conjunto de técnicas parciais, mas complementares, explicar e sistematizar 
o conteúdo da mensagem e o significado desse conteúdo, por meio de deduções lógicas e justificadas, tendo como referência sua origem (quem emitiu) e o contexto da mensagem ou os efeitos dessa mensagem.

Nesse processo, faz-se necessário considerar a totalidade de um "texto", passando-o pelo crivo da classificação ou do recenseamento, procurando identificar as freqüências ou ausências de itens, ou seja, categorizar para introduzir uma ordem, segundo certos critérios, na desordem aparente.

O momento da escolha dos critérios de classificação depende daquilo que se procura ou que se espera encontrar. O interesse não está na simples descrição dos conteúdos, mesmo que esta seja a primeira etapa necessária, para se chegar à interpretação, mas em como os dados poderão contribuir para a construção do conhecimento após serem tratados.

Os conhecimentos deduzidos podem ser de natureza psicológica, sociológica, histórica, econômica, por isso, a intenção da análise de conteúdo é a inferência ${ }^{2}$ de conhecimentos relativos às condições de produção ou de recepção. O pesquisador procura, com base nas categorias estabelecidas, inferir, ou seja, extrair uma conseqüência, deduzir de maneira lógica conhecimentos sobre o emissor da mensagem ou sobre o contexto em que esta foi emitida.

Precisa ficar claro, como dizem Henry e Moscovici (1968) apud Bardin (1979, p.40), que:

Qualquer análise de conteúdo não visa o estudo da língua ou da linguagem, mas sim a determinação mais ou menos parcial do que chamaremos as condições de produção dos textos, que são o seu objeto. O que tentamos caracterizar são estas condições de produção e não os próprios textos. $\mathrm{O}$ conjunto das condições de produção constitui o campo das determinações dos textos.

A expressão condições de produção foi considerado por Bardin um tanto vaga, por isso, ela prefere usar a denominação: variáveis inferidas, a qual possibilita considerar tanto a produção como a inferência sobre a recepção da mensagem. Não importa o termo usado, é preciso articular a superfície dos textos, descritas e analisadas, pelo menos em alguns elementos característicos e os fatores que determinaram estas características, deduzidas logicamente. (1979, p.40)

Toda análise de conteúdo que se faz de um "texto" ${ }^{3 "}$ está fundamentada em princípios filosóficos e teóricos, que permeiam a estrutura de pensar do pesquisador. A produção científica está diretamente relacionada às demandas do momento histórico, assim como às possibilidades oferecidas ao seu desenvolvimento. O conhecimento científico resulta da ação dialógica entre as complementaridades e antagonismos da razão, da experiência, da imaginação 
e da verificação. Esse conhecimento não pode, assim, de modo algum, ser dissociado da vida humana e da relação social.

\section{Análise de conteúdo e pesquisa na área de educação}

As ciências humanas, na metade do século XIX, passaram a seguir o modelo das ciências da natureza, e em seus estudos e pesquisas procuraram as características do empirismo, da objetividade, da experimentação, da validade. Um modelo que muito cedo teve reconhecido seus limites e inadequações ao objeto de estudo (o ser humano).

Os pesquisadores, principalmente da área social, se utilizam usualmente de abordagens de pesquisa que levam a dados que não possuem atributos de quantidade diretamente associados. Procedimentos como a entrevista, o questionário, com questões abertas que precisam ser descritas, analisadas e interpretadas, entre outros, são exemplos deste tipo de dado.

A análise de conteúdo desenvolve um arcabouço formal para a sistematização de atributos qualitativos, e no momento de interpretar os dados coletados $^{4}$ que se dá o entrelaçamento da pesquisa em educação com a análise de conteúdo. A essência deste formalismo é estatística, pela sua concepção e forma de compilação, uma análise de conteúdo leva a métodos estatísticos multivariados.

Por esta abrangência metodológica, a análise de conteúdo é também uma das técnicas mais utilizadas, ajudando o pesquisador, seja ele mestrando, doutorando, professor universitário, participante de programas de iniciação científica a identificar a significação do texto que está se analisando.

Na área de educação, a análise de conteúdo pode ser, sem dúvida, um instrumento de grande utilidade em estudos, em que os dados coletados sejam resultados de entrevistas (diretivas ou não), questionários abertos, discursos ou documentos oficiais, textos literários, artigos de jornais, emissões de rádio e de televisão. Ela ajuda o educador a retirar do texto escrito seu conteúdo manifesto ou latente.

\section{0 que é a nálise de conteúdo?}

Pode-se dizer que a análise de conteúdo é um conjunto de técnicas de exploração de documentos, que procura identificar os principais conceitos ou os principais temas abordados em um determinado texto. Ela começa, geralmente, por uma leitura flutuante por meio da qual o pesquisador, num trabalho gradual de apropriação do texto, estabelece várias idas e vindas entre 
o documento analisado e as suas próprias anotações, até que comecem a emergir os contornos de suas primeiras unidades de sentido. Estas unidades de sentido - palavras, conjunto de palavras formando uma locução ou temas são definidas passo a passo e guiam o pesquisador na busca das informações contidas no texto.

O objetivo de toda análise de conteúdo é o de assinalar e classificar de maneira exaustiva e objetiva todas as unidades de sentido existentes no texto. Além de permitir que sobressaiam do documento suas grandes linhas, suas principais regularidades.

A definição precisa e a ordenação rigorosa, destas unidades de sentido, ajudarão o pesquisador a controlar suas próprias perspectivas, ideologias e crenças, ou seja, controlar sua própria subjetividade, em prol de uma maior sistematização, objetividade e generalização dos resultados obtidos.

O objetivo final da análise de conteúdo é fornececer indicadores úteis aos objetivos da pesquisa. O pesquisador poderá, assim, interpretar os resultados obtidos relacionando-os ao próprio contexto de produção do documento e aos objetivos do indivíduo ou organização/instituição que o elaborou.

\section{As etapas de ex ecução da Análise de Conteúdo: do qualita- tivo à esta tística}

As etapas que permitem ao pesquisador definir e classificar as unidades de sentido e, assim, desvendar significações novas e, muitas vezes, inesperadas do documento exigem a obediência a um certo número de etapas, 0 domínio de um certo número de técnicas e o trilhar de um caminho, que começa pela realização de operações qualitativas e termina com a aplicação de modelos estatísticos. $\mathrm{O}$ rigor de execução não implica, porém, rigidez. Ao contrário, a análise de conteúdo permite ao pesquisador escolher entre uma gama de métodos, técnicas e operações, a condição para que estes sejam claramente definidos.

Trata-se de um procedimento antes de tudo pragmático, cuja legitimização depende essencialmente do conjunto de operações adotadas na pesquisa. Neste sentido, o pesquisador deverá fundamentar suas ações, justificando sempre a organização do trabalho, assim como a confiabilidade e a validade de seus instrumentos.

A seguir, de maneira sucinta, são descritas as principais etapas do desenvolvimento de uma análise de conteúdo.

\section{Orga niza ção do ma terial de trabalho}

Uma vez que a análise de conteúdo foi julgada pelo pesquisador 
como sendo o melhor método para responder aos objetivos globais de sua pesquisa, é necessário constituir e organizar o material de trabalho. Este poderá, por exemplo, ser composto de entrevistas transcritas de alunos, professores, funcionários da escola, documentos emitidos pelo Ministério da Educação e Cultura, artigos de jornais, etc. Uma vez tendo sido reunido o material, ele deverá ser previamente organizado, tendo em vista a sua manipulação. Os textos poderão ser reescritos em fichas, fotocopiados, impressos, segundo a vontade do pesquisador. O essencial é que sua manipulação seja fácil e possa ser feita com uma certa rapidez. Em caso de análise informática, o texto deverá ser preparado conforme as exigências do software utilizado.

E aconselhável ainda, dependendo do tipo de análise de conteúdo escolhido pelo pesquisador e do volume do material a ser analisado, proceder a uma amostra representativa aleatória, levar em consideração as variáveis e definir sobre a pertinência destas para a análise dos dados. Se for o caso, em um primeiro momento, é melhor que sejam analisados unicamente os documentos da amostra. Os resultados obtidos servem de guia, em seguida, será analisado todo o conjunto da pesquisa, inclusive a amostra previamente selecionada.

Por exemplo, se o pesquisador tem em mãos um total de trinta entrevistas, poderá estabelecer uma amostra aleatória de cinco entrevistas e em um momento inicial classificar apenas o conteúdo destas cinco entrevistas. Os resultados servirão como guia para uma análise posterior de todas as entrevistas.

\section{Definição das unidades de registro}

A segunda etapa consiste na definição das unidades de registro, que serão utilizadas pelo pesquisador. Estas, como já foi dito, podem ser constituídas por palavras, conjunto de palavras (que pode corresponder, entre outros, a slogans, pronomes, locuções adverbiais, locuções verbais...) ou temas. Alguns pesquisadores poderão ainda adotar, como unidade de registro, um personagem, um acontecimento ou até mesmo um objeto. Os objetivos da pesquisa, assim como uma primeira leitura dos textos, ajudarão a determinar a(s) unidade(s) de registro pertinentes para a pesquisador. Se a escolha do pesquiador repousar sobre um personagem, acontecimento ou objeto, ele poderá defini-lo por palavra ou conjunto de palavras. Uma vez que o tipo de unidade de registro foi definido, o pesquisador procede por reconhecimento, buscando situá-lo no texto.

Segundo Urung (1974), as unidades de registro podem ser classificadas em função de dois critérios: os critérios formais e os critérios semânticos. Se a unidade de registro escolhida pelo pesquisador for a palavra, e ele quiser classificá-la de acordo com critérios formais, isto significa que ele levará em 
consideração o grupo gramatical ao qual a palavra pertence: substantivo, adjetivo, verbo... Trata-se de um procedimento estilístico quantitativo utilizado, por exemplo, em certas análises ideológicas de discurso. Se o pesquisador decidir classificar a palavra de acordo com critérios semânticos, ele se interessará ao seu sentido (polissêmico, sinonímico, mudanças de sentido, relações reunindo as unidades significantes).

Ao contrário da palavra, o tema é classificado unicamente em categorias semânticas. Este procedimento é empregado, com grande freqüência, em pesquisas (a maior parte dos trabalhos de análise de conteúdo utiliza o tema como unidade de registro), sua delimitação é, portanto, uma tarefa delicada. O conjunto de palavras, uma vez definido pelo seu valor semântico, também é considerado como tema.

\section{Definição e delimitação do tema}

Segundo Moscovici (1976, p. 293-294), o tema é "geralmente uma proposição tipo que exprime toda uma familia de proposições tendo relação com um mesmo conteúdo diversamente formulado [...] Sua função é a de resumir o conteúdo". Assim, ele aparece "como uma assertiva tornando possível um conteúdo variável. Ele constitui ao mesmo tempo uma relação na medida em que serve de mediador entre uma parte do conjunto com uma outra".

Segundo Urung (1974, p. 26), "o tema pode ser evocado em uma única afirmação ou desenvolvido em uma passagem de texto inteira; ele pode aparecer sob forma de uma alusão em um detalhe (a escolha de uma palavra ou mesmo uma forma gramatical) ou estar presente, difuso, dentro de uma passagem".

A afirmação de Urung revela o que pode ser uma grande dificuldade da análise de conteúdo baseada no tema: onde se deve operar o corte, estabelecendo os limites do tema?

No exemplo dado pela pesquisa, realizada por Oliveira (1997), sobre representação social e imagem das crianças de rua veiculada pela imprensa, pode-se analisar a delimitação temática na construção da categoria uso de drogas.

O tema pode ser evocado em uma única frase:

Segundo os moradores, os menores tem o hábito de se agrupar e cheirar cola em plena luz do dia (Jornal O Globo),

ou ser desenvolvido em uma passagem (implicando então em sua formulação a redação de várias frases):

Estas crianças fazem uso de drogas e é dever do Estado protegê-las, afirmou o Juiz. Por sua decisão, os menores dependentes de drogas como maconha 
e cocaína terão um dossiêr junto da Divisão de Proteção a Criança e ao Adolescente, sendo em seguida enviadas para o Conselho Tutelar. Marcia Juliano, delegada da DPCA aprova esta medida: "estas crianças não podem tomar sozinhas a decisão de abondonar o vício. Elas precisam de ajuda do Estado" (Jornal O Globo), "O incidente aconteceu logo após a parada do ônibus da linha 388 na Avenida Chile, onde o chofer pediu ajuda ao Sargento João Rodrigues, do $13^{\circ}$ Batalhão de polícia, para tirar as crianças de dentro do ônibus, pois elas cheiravam cola e faziam barulho. $\mathrm{O}$ sargento tirou as crianças e na rua foi ajudado por um homem branco, vestindo uma roupa escura. (Jornal O Globo).

\section{Definição de categorias}

A terceira etapa da pesquisa consiste na definição das categorias. Esta etapa é muito importante, pois a qualidade de uma análise de conteúdo possui uma dependência como o seu sistema de categorias. A categorização gera classes que reúnem um grupo de elementos da unidade de registro. As classes são compiladas a partir da correspondência entre a significação, a lógica do senso comum e a orientação teórica do pesquisador. Portanto, os critérios para a categorização podem ser semânticos; sintáticos; léxico ou expressivos. Ainda, Bardin (1979) indica a possibilidade de uma categorização com categorias a priori, sugeridas pelo referencial teórico e com categorias $a$ posteriori, elaboradas após a análise do material.

O sistema de categorização é composto por um reagrupamento progressivo de categorias, cuja amplitude varia de uma forte generalidade até uma generalidade fraca, como é o caso da sub-categoria. Bauer (2000) sugere que todas as unidades de registro sejam categorizadas mesmo que para isso deva se criar categorias, tais como: "outro" ou "não se aplica", e que as categorias devem ser exclusivas e auto-excludentes sob pena de haver problemas quanto a fidedignidade. Além disso, as categorias a posteriori devem ser construídas, levando em consideração a orientação teórica e os objetivos da pesquisa.

Bardin (1979) indica que uma boa categoria deve suscitar a exclusão mútua, a homogeneidade, a pertinência, a objetividade e fidelidade e a produtividade. Bauer (2000) sugere princípios para aquilo que ele chama de qualidade na análise de conteúdo, destacando: a) coerência e simplicidade do referencial de codificação, b) transparência da documentação, c) fidedignidade, d) validação, e) boa resolução dos três principais dilemas estabelecidos na análise de conteúdo ${ }^{4}$.

Com relação à coerência e simplicidade da codificação, destaca-se a indicação de um único princípio ordenador da atribuição das categorias, tal princípio deve estar pautado em idéias superiores que organizarão o referencial 
de codificação de forma coerente. A partir do princípio ordenador, tem-se as noções primárias que se desmembram em categorias secundárias ou sub-categorias.

A seguir, o exemplo do trabalho de Oliveira, no qual a unidade de registro "tema" orientou a leitura dos artigos dos jornais O Globo e Folha de São Paulo. No total, a pesquisa reuniu 35 temas que foram, em seguida, reagrupados em 15 categorias. Três destas categorias estão descritas abaixo - Definição da Criança de Rua, Rua e Família, acompanhadas por seus respectivos temas.

\section{Definição (tipologia) da criança de rua}

A criança de rua é definida em função das características de seu corpo (masculino, feminino, negro, índio, ...)

A criança de rua é definida em função de sua estrutura física (imagem negativa de si-mesmo, agressividade, ternura... )

A criança de rua é definida em função de comportamentos próprios a sua idade (correr, brincar, ...)

A criança de rua é definida em função de seu percurso escolar (semianalfabeto, fracasso escolar, ...).

A criança de rua é definida em função do trabalho (trabalhador, trabalhador autônomo, ...)

A criança de rua é definida em função da lei (delinqüente, traficante de drogas ...).

A criança de rua é definida em função dos maus tratamentos recebidos (uma criança de rua é uma criança maltratada)

A criança de rua é definida em função de seu pertencimento a grupos desfavorecidos (excluídos, miséraveis, ..)

\section{Rua}

A rua é um lugar onde a criança escolhe ficar (diversão, liberdade, ...)

A rua é um lugar onde a criança permanece por falta de opções (a rua é um lugar de sobrevivência)

A rua é um lugar onde a criança está exposta ao perigo

A rua é um lugar onde a criança coloca o outro em perigo

\section{Família}

A familia da criança é desestruturada (grande pobreza, promiscuidade, violência, alcoolismo,...)

A familia da criança é bem estruturada (presença dos dois pais, solidariedade entre os membros da família..) 
As categorias podem, ainda, ser previamente construídas (análises por categorias previamente construídas) ou podem ser definidas à medida que estas forem encontradas no texto (análises semânticas inferidas do texto). Naturalmente, este não é um processo rígido. Um pesquisador que tenha prédefinido suas unidades de registro (e suas categorias) poderá remanejá-las depois de ter realizado uma primeira leitura do texto.

O trabalho de Feitosa Andrade (2001) oferece um exemplo deste processo. Em seu trabalho sobre estigma, ideologia e imagem da prostituição infanto-juvenil, veiculada pela mídia, a unidade de análise referente ao pertencimento étnico-racial das crianças e adolescentes foi banida, pois não constavam nos artigos de jornais. As categorias que guiaram Andrade (2001) na leitura do jornal Folha de São Paulo estão ilustradas na grade - figura 1.

FIGURA 1 - Grade sobre o tema

\section{ATRIBUTOS UTILIZADOS PARA DESCREVER OS PERSONAGENS NA PROSTITUIÇÃO INFANTO-JUVENIL}

\begin{tabular}{|c|c|}
\hline \&. & $\begin{array}{l}\text { Número da Personagem } \\
\text { UI } \\
\text { Ano } \\
\text { Caso } \\
\text { Região }\end{array}$ \\
\hline \multirow{3}{*}{ 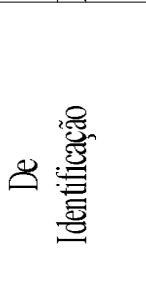 } & $\begin{array}{l}\text { Tipo de personagem } \\
\text { Identificação da(s) personagem(ns) } \\
\text { Idade } \\
\text { Sexo }\end{array}$ \\
\hline & $\downarrow$ Somente para o sexo femi nino \\
\hline & $\begin{array}{l}\text { Escolaridade } \\
\text { Região de procedência } \\
\text { Outra atividade } \\
\text { Vínculo familiar }\end{array}$ \\
\hline 蚫 & $\begin{array}{l}\text { Idade de início na prosti tuição } \\
\text { Tempo na prosti tuição } \\
\text { Remuneração } \\
\text { Local da atividade } \\
\text { Coadjuvante } \\
\text { Saúde } \\
\text { Finalidade da remuneração }\end{array}$ \\
\hline 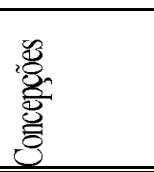 & $\begin{array}{l}\text { Justificativa p/a entrada na PIJ } \\
\text { Justificativa p/ a permanência na PIJ } \\
\text { Prognóstico de vida }\end{array}$ \\
\hline
\end{tabular}




\section{A codagem (enumeração) e a ná lise freqüencial}

A construção de uma grade, seja ela baseada em palavras, conjunto de palavras ou temas, definidos previamente ou não, depende de um sistema de codagem. Cada palavra, conjunto de palavras ou temas assinalados no texto, assim como cada categoria, deve ser precedida por um número. A grade deverá também ser submetida a uma análise freqüencial que permitirá saber quantas vezes determinado tema ou palavra aparece no texto.

A análise de freqüência pode ser feita intergrupo ou intragrupo. Na contagem intergrupo cada unidade de sentido que aparecer duas vezes ou mais em um texto só será considerada uma única vez. Na contagem intragrupo, o pesquisador levará em conta o número de vezes que cada unidade de sentido aparecer no texto. A ordem de aparição da unidade de sentido no texto poderá ainda ser ou não considerada na contagem freqüencial. A decisão de realizar uma contagem intergrupo ou intragrupo depende das questões feitas pelo pesquisador e dependerá dos objetivos da pesquisa.

\section{Qualidade na a nálise: a questão da transparência da documenta ção e da fidedignidade da a nálise}

A transparência da documentação exige do pesquisador a construção de registros explicativos dos procedimentos e decisões tomadas no curso da análise de conteúdo.

Os registros necessários compreendem: lista sumária das categorias; distribuição das freqüências com a devida numeração e definição; e o caderno de códigos, definido como uma unidade de texto ilustrativa que se aplica a cada categoria. Ainda é preciso assegurar a discussão sobre como o pesquisador tratou a questão da fidedignidade da codificação e do tempo exigido para que tal processo fosse considerado aceitável.

Para Bauer (2002), a transparência em pesquisa é uma espécie de "prestação pública de contas", servindo de suporte para futuras replicações.

O grau aceitável de concordância entre os intérpretes ou codificadores é denominado fidedignidade ${ }^{5}$. Neste caso, pode-se verificar a fidedignidade de uma matriz de categorização a partir de, no mínimo, duas codificações que podem ser elaboradas por um codificador em dois momentos diferentes ou por dois ou mais grupos de codificadores que codificam o material, ao mesmo tempo.

Para determinar o grau de concordância entre as codificações, Bauer (2000) sugere os índices de fidedignidade (phi, kappa ou alpha).

\section{Análise estatistica multivariada e interpretação}

A análise da distribuição de freqüências fornece um parâmetro estatístico preliminar para a avaliação do padrão de respostas obtido. Mas, conforme 0 
número de unidades de análise e a complexidade das hipóteses a serem testadas, é necessário utilizar modelos matemáticos mais robustos. Neste caso, os chamados modelos mais robustos.

A busca pela fidedignidade na análise de conteúdo implica em procedimentos estatísticos que, conforme Bauer (2000), podem ser utilizados para mensurar o grau de concordância entre os codificadores.

Para tanto, modelos estatísticos multivariados surgem como procedimentos adequados para fundamentar a interpretação dos resultados e testar a sua consistência 6 .

Para explorar essa questão, faz-se necessário percorrer um modelo de análise que explicita todo o encadeamento de procedimentos necessários ao cumprimento das etapas de uma análise de conteúdo, com destaque ao tratamento estatístico.

O algonítmo presente na figura 2 apresenta uma proposta de um modelo experimental estatístico multivariado, aplicado à análise de conteúdo, quatro fases o determinam.

FIGURA 2 - Algorítmo: modelo de análise

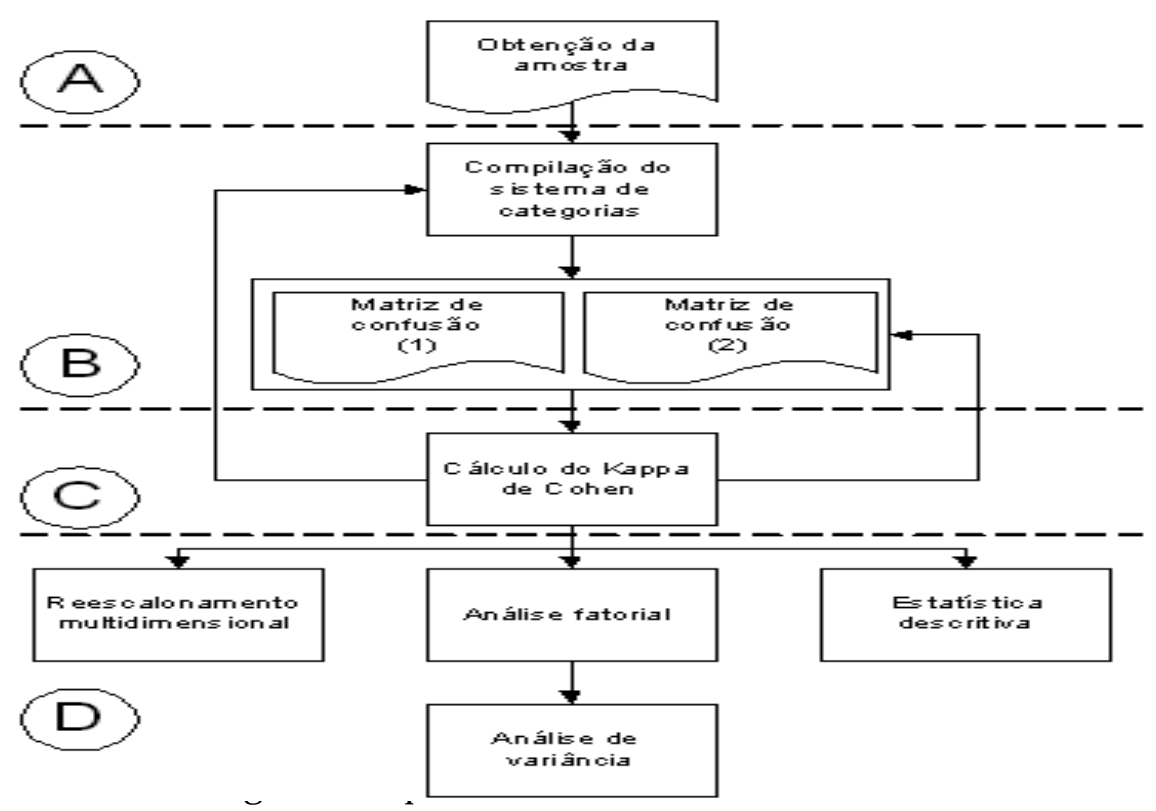

As fases "A" e "B" corresponde a etapas já supracitadas referentes à compilação de uma amostra aleatória ${ }^{7}$ e à compilação de uma estrutura de categorias ${ }^{8}$. 
Neste modelo, um procedimento estatístico de comparação de classificações independentes é proposto para se avaliar a consistência estatística do desenho do sistema de categorias. No caso duas, ou mais, classificações das parcelas experimentais por conjuntos de pesquisadores, ou amostras, independentes fornecem subsídios para um procedimento estatístico.

Uma "matriz confusão" (tabela 1) compila os resultados de um conjunto de juízes, esta matriz associa às suas colunas ao sistema de categorias, no caso definidas como variáveis binárias, e as linhas correspondem às parcelas experimentais.

TABELA 1- Representação da "matriz de confusão"

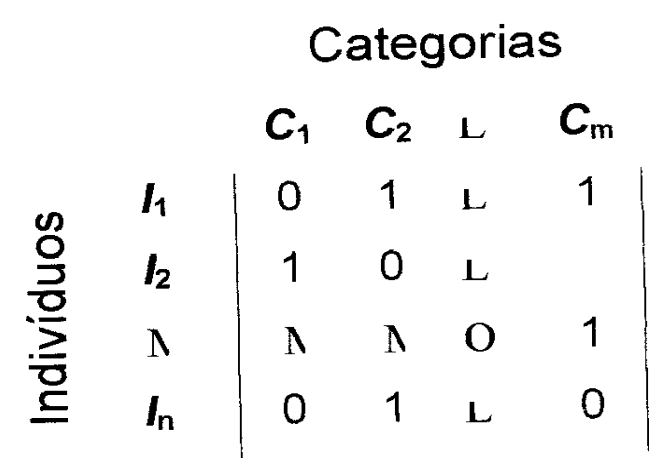

O fim da Fase "B" e a Fase "C" refletem uma opção de modelo experimental. Para este trabalho optamos, apenas como opção e exemplo, por dois grupos de juízes trabalhando de forma independente em uma mesma amostra. Por este desenho experimental, pode-se aplicar uma estatística de dados emparelhados, um modelo adequado é o Kappa de Cohen ${ }^{9}$.

Essa estatística varia de 0 a 1, ajuste nulo e máximo, respectivamente. Os resultados obtidos podem ser avaliados por um teste estatístico convencional ${ }^{10}$, se o resultado for não significativo (a um nível de significância de 5\%), entre os procedimentos abaixo, ao menos um será necessário:

1. Reavaliação dos critérios de classificação;

2. Compilação do sistema de categorias;

3. Classificação de uma nova amostra e avaliação do ajuste.

A Fase " $\mathrm{D}$ " se caracteriza pela aplicação de modelos estatísticos multivariados. São usuais os seguintes modelos: análise fatorial, análise de variância e reescalonamento multidimensional ${ }^{11}$.

Esses modelos não são mutuamente exclusivos, a sua combinação 
em diversas estratégias metodológicas pode levar a resultados complementares, além de potencializar mais possibilidades de avaliação da verossimilhança dos resultados obtidos.

\section{Os limites da análise de conteúdo}

Mesmo se do ponto de vista técnico, o desenrolar da análise de conteúdo responde a um bom nivel de rigor, algumas críticas são feitas, lembrando os limites de toda análise de conteúdo. Assim, a análise de conteúdo temática tem sido considerada subjetiva e até mesmo impressionista, pois desde 0 início ela repousa sobre uma atividade interpretativa e uma "codificação intuitiva" do pesquisador.

Não se enquadrando totalmente nos limites rigorosos de uma definição científica, a análise de conteúdo temática acorda, no entanto, algumas vantagens aos pesquisadores que decidem empregá-la. Assim, ela ultrapassa os limites de uma análise limitada unicamente ao conteúdo manifesto. A opção de realizar uma análise temática, em detrimento de uma análise de conteúdo manifesto, na qual os dados seriam plenamente quantificáveis, justificase pela vontade de se compreender o sentido pleno do discurso, inclusive 0 de assinalar os seus conteúdos latentes.

Uma segunda questão colocada àqueles que optam pela análise de conteúdo - temática ou não - como método, diz respeito à interpretaçao de resultados feita por critérios que previlegiam a freqüência. Ao se tomar como respostas palavras de Ghiglione et al (1980) sobre a análise de conteúdo feita a partir de entrevistas

De fato, nada garante que um tema freqüente é necessariamente um tema importante ou, ao contrário, que um tema pouco freqüente não esteja em relação com uma representação essencial, porém reprimida ou dificilmente verbalizada [...]. O fato que um tema seja freqüentemente abordado em uma entrevista pode simplesmente querer dizer que ele esta mais disponivel nos esquemas de conversa, o que evidentemente não deixa entrever em nada a importância deste tema no sistema de representações sobre o assunto.

Mesmo sendo imperfeita, a interpretação baseada em freqüências é um modo de definir o conteúdo relacionado a determinado assunto, e permite ao pesquisador reconstitutir um corpo de representações. Se bem executada, os resultado obtidos fornecem uma base formal estável para o desenvolvimento de modelos estatísticos multivariados e, enfim, potencializar a apreensão das significações inerentes ao objeto de estudo.

A análise de conteúdo oferece um modelo experimental bem defini- 
do, que parte de uma concepção orientada ao entendimento do objeto de estudo ${ }^{12}$, e, para tanto, se utiliza de modelos que garantem uma interpretação formal dos resultados com espaço para a criatividade, mas sem abrir mão do ideal de reprodutibilidade e transparência das condições experimentais. Sem ser um método perfeito, se configura como um procedimento confiavél para atingir as linhas mestras de um texto.

\section{Notas}

1 Texto organizado a partir dos encontros na disciplina-projeto: Mapas Mentais, Programa de Pós-Graduação em Educação: Psicologia da Educação, Pontíficia Universidade Católica de São Paulo. Sob a responsabilidade da Prof. a Dr. $^{\text {a }}$ Clarilza Prado de Souza.

2 Inferência é a operação lógica, pela qual se admite uma proposição em virtude da sua ligação com outras proposições já aceitas como verdadeiras". (BARDIN, 1979, p. 39)

3 Para Bardin (1979, p. 39) "dois tipos de documentos podem ser submetidos a análise: documentos naturais, produzidos espontaneamente na realidade; e documentos suscitados pelas necessidades de estudo (por exemplo: respostas a questionários de inquéritos, testes, experiências, etc.)".

4 E conseqüente ajuste entre a interpretação e o modelo formal.

5 Observação das relações estabelecidas entre: 1) amostragem e codificação, 2) espaço de tempo e complexidade da codificação e 3) fidedignidade e validade.

6 Fidedignidade refere-se àquilo que é digno de crédito, de confiança, de fé.

7 Por consistência entende-se: estabilidade de opinião ou de comportamento por parte de um ou mais codificadores. Diz-se que a codificação está consistente quando apresenta ausência de contradição, coerência lógica; compatibilidade.

8 E resultante de uma "leitura flutuante" do corpus obtido, a qual possibilita uma avaliação inicial do corpus.

9 Sendo esta imanente de uma "leitura formal" do corpus.

10 Novamente, esta opção configura apenas um exemplo. Para este caso uma outra possibilidade é o teste de simetria de McNemar. Em outros desenhos experimentais, estatísticas diferentes poderiam ser propostas com resultados semelhantes.

11 Suplementado por uma simulação de Monte Carlo.

12 Destacamos estes modelos, mas diversos outros modelos podem ser adotados, como exemplo: a análise de agrupamento, a análise de classificação hierárquica implicativa e a análise de discriminante.

13 Trabalha, sem dicotomia, com atributos, com maior e menor potencial de quantificação.

\section{Referências}

ABRIC, Jean-Caude. Méthodes d'étude des représentations sociales. 
Ramonville Saint-Agne: Érès, 2003.

ANDRADE, Leandro Feitosa. Prostituição infanto-juvenil na midia: estigmatização e ideologia, São Paulo, 2001. Tese (Doutorado em Psicologia Social) - Pontifícia Universidade Católica de São Paulo - PUC-SP.

BARDIN, Laurence. Análise de conteúdo. Lisboa: Edições 70, 1995.

BAUER, M.W; GASKELL, G. Pesquisa qualitativa com texto, imagem e som: um manual prático. Petrópolis: Vozes, 2002.

DELHOME, Patricia; MEYER, Thierry. Les projets de recherche en psychologie Sociale. Paris: Armand Colin,1997.

GHIGLIONE,Rodolphe; BEAUVOIS, Jean Léon; CHABROT, Claude; TROGNON, Alain. Manuel d'analyse de contenu. Paris: Armand Colin,1980,.

OLIVEIRA, E. Communication de masse et repréntations sociales: communication de massa et representation sociale: l'image del'enfant de la rue dansla presse brésilienne, Paris, 1997. Dissertação (Mestrado de Psicologia Social) - Universidade de Paris, Ecole des Hautes Etudes en Sciences Sociales.

REINERT, Marx. Alceste une methodologie d'analyse des donnes textuelles et une application: aurelia de Gerard de Nerval. Bulletin de méthodologie sociologique, n.26, p.24-54, mar. 1990.

URUNG, Marie-Christine. Analyse de contenu et acte de parole. Paris: Editions Universitaires, 1974. 